\title{
Erratum to: Comorbidity and Mortality in Heart Failure
}

Juan I. Pérez-Calvo, MD, $P h D^{7}$, Manuel Montero-Pérez-Barquero, MD, PhD², and Francesc Formiga, $\mathrm{MD}, \mathrm{PhD}^{3}$

'Department of Internal Medicine, Hospital Clínico Universitario "Lozano Blesa", Zaragoza, Spain; ${ }^{2}$ Hospital Universitario Reina Sofía, Córdoba, Spain; ${ }^{3}$ Hospitalet de Llobregat, Universitario de Bellvitge, Barcelona, Spain.

J Gen Intern Med 27(11):1571

DOI: $10.1007 / \mathrm{s} 11606-012-2216-0$

(c) Society of General Internal Medicine 2012

\section{Erratum to: J Gen Intern Med}

DOI: 10.1007/s11606-012-2110-9

$\mathrm{O}$ n page 892 of the original publication, the title of the letter should be: Comorbidity and Mortality in Heart

Failure

Corresponding Author: Juan I. Pérez-Calvo, MD, PhD; Department of Internal Medicine, Hospital Clínico Universitario "Lozano Blesa" 50009 Zaragoza, Spain (e-mail: jiperez@unizar.es).

The online version of the original article can be found at http:// dx.doi.org/10.1007/s11606-012-2110-9.

Published online September 4, 2012 